\title{
Reliability Analysis on One-Step Overall Transportation of Composite Bucket Foundation for Offshore Wind Turbine
}

\author{
Jijian Lian ${ }^{1,2,3}$, Pengwen Wang ${ }^{1,2}$, Conghuan Le ${ }^{1,2, * \mathbb{C}}$, Xiaofeng Dong ${ }^{1,2}$, Xu Yang ${ }^{1,2}$, \\ Qi Jiang ${ }^{1,2}$, Yilin Yang ${ }^{1,2}$ and Junni Jiang ${ }^{1,2}$ \\ 1 State Key Laboratory of Hydraulic Engineering Simulation and Safety, Tianjin University, Tianjin 300350, \\ China; jjlian@tju.edu.cn (J.L.); jiemaoji@tju.edu.cn (P.W.); xiaofeng.dong@tju.edu.cn (X.D.); \\ yang_xu90@tju.edu.cn (X.Y.); jiangqi_tju@163.com (Q.J.); yangyilin0716@tju.edu.cn (Y.Y.); \\ jjn_zjqz@126.com (J.J.) \\ 2 School of Civil Engineering, Tianjin University, Tianjin 300072, China \\ 3 School of Water Conservancy and Hydroelectric Power, Hebei University of Engineering, Handan 056002, \\ Hebei Province, China \\ * Correspondence: leconghuan@163.com
}

Received: 28 October 2019; Accepted: 14 December 2019; Published: 19 December 2019

\begin{abstract}
Composite bucket foundations, which have been successfully transported, installed, and operated at the Qidong, Xiangshui, and Dafeng offshore wind farms in China, are economically advantageous due to the relatively simple transportation and installation process. The innovative one-step transportation and installation technology of foundation-tower-nacelle is the key phase in saving costs. In this paper, a "foundation lift ship" overall transport mode is proposed and introduced for the first time. Prototype data measurement, preliminary numerical simulation, and theoretical calculations were conducted to investigate whether the foundation-ship integrity, tower hoop stability, and various indexes of the nacelle met the requirements under the influences of various environmental factors. The multi-system coupling motion mechanism and analysis method of this new structure and transportation mode were expounded. Through the prototype observation data of the one-step overall transportation, the ship-foundation system reliability of the structure in the case of large wind and wave was confirmed. Furthermore, it was found that in the one-step overall transportation, the importance of factors to nacelle acceleration decreased in the order of wave height, current speed, and wind speed by the time and frequency domain analysis and data statistics.
\end{abstract}

Keywords: offshore wind turbine (OWT); composite bucket foundation (CBF); one-step overall transportation; prototype observation; wind-wave-current coupling analysis

\section{Introduction}

With the rapid development of the world economy and the increasing energy consumption, the utilization of new renewable energy is an inevitable trend of social development. Marine renewable energy is playing an increasingly important role in the energy framework due to the geographical and environmental limitations of inland renewable energy. Compared with the construction of onshore wind farms, offshore wind farms are faced with a more complicated and harsh offshore environment, which makes their construction more difficult and have a lower operational period, thus greatly increasing the cost and time limit of offshore wind power development.

At present, the European offshore wind power costs have fallen rapidly. Germany has reached $98.3 € / \mathrm{MWH}$ of the bidding price, compared with the China's cost staying between $125.5-180.5 € / \mathrm{MWH}$, which is not only a large gap with the European developed countries, and is also higher than the price 
of $108.8 € / \mathrm{MWH}$ for offshore wind power and $96.03 € / \mathrm{MWH}$ for intertidal wind power. According to the 13th Five-Year Plan of China, the cumulative installed capacity of wind power will exceed $210 \mathrm{GW}$ by the end of 2020, among which the installed capacity of offshore wind power will reach more than 5 GW [1]. Offshore wind power will make a substantial contribution to China's energy policy goals.

In the face of the huge scale of offshore wind power development and the urgent need to reduce the cost of offshore wind power development, we mainly conducted this study through two aspects of efforts. The first is to reduce the cost of wind turbines and their supporting facilities while increasing the capacity of individual units, while the second was to improve and optimize the offshore wind farm construction technology and corresponding construction equipment toward the goal of "safety, economy, and efficiency".

At present, the established offshore wind farms adopt offshore fixed infrastructure, mainly monopile-base foundations and high pile cap foundations. As offshore wind gradually moves toward the direction of "deep sea + large capacity", it will make the existing offshore wind fixed support structure face more difficult problems. For example, increases in monopile thickness, diameter, and length will cause great difficulties to the pile driving precision and construction equipment, and will sharply increase the construction period and cost. Jackets, multi-leg brackets, pile-cap foundations, and other methods can increase the bearing capacity of the foundation by increasing the pile spacing, but there is still no way of avoiding piling, hoisting, connection, steel structure, concrete construction, and other offshore operation procedures, which are finally reflected in the high construction cost and long construction period.

Bucket foundations have been widely used on the basis of floating offshore platform mooring anchors, and have gradually been introduced into offshore wind power infrastructure. In recent years, bucket foundations, as a type of new offshore wind power foundation, has attracted more and more attention. Bucket foundation can be divided into three kinds: single bucket foundation, multi-bucket foundation, and composite bucket foundation. At present, all kinds of bucket foundations have been used worldwide.

The composite bucket foundation (CBF), which was put forward by Tianjin University in 2008 has been proven to be applicable and economically advantageous to offshore wind turbines due to its innovative one-step overall transportation technology (Figure 1) [2-6]. For traditional offshore wind turbines, the installation of a complete wind turbine structure is divided into two stages, with the foundations and turbines installed at different times. In the one-step overall transportation technology, the foundations and turbines are installed at the same time. This can commendably reduce the cost of construction time and the process of the offshore operations as well as the demand for large-scale maritime transport and installation equipment $[7,8]$.

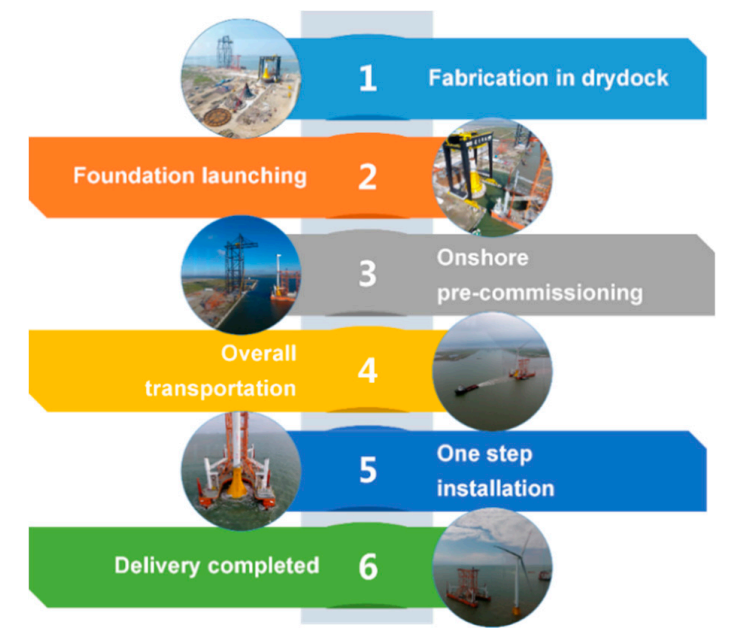

Figure 1. One-step overall transportation technology of the CBF. 
According to the statistics shown by Lacal-Arntegui et al. [9] on the installation of monopile-base foundations, the installation of the whole set was about five days (2.5 days for the foundation installation and 2.5 days for the wind turbine) in 2018, while the installation process of the CBF was controlled within 10-15 h, according to the actual projects. The construction time was greatly saved, so the construction cost of the whole set could be reduced to $70 \%$ of the current offshore wind power foundation construction and wind turbine installation cost, which has an obvious competitive advantage [7].

The CBF and the technique process have been promoted to several offshore wind farms. In 2010, the first 2.5 MW intertidal CBF wind turbine prototype was successfully installed and applied in Qidong, Jiangsu Province, China. In 2017, two 3 MW CBF wind turbines were installed in Xiangshui wind farm and connected to the grid in the same year. At the end of June 2019, eleven 3.45 MW wind turbines and two 6.45 MW ones of CBF were installed at Dafeng wind farm.

The wet towing of a ship-foundation system is the key technique of one-step overall transportation, which consists of a one-step dedicated ship, a 3.45 MW wind turbine, and a CBF, as shown in Figure 1 .

Traditional towing methods can provide references for the present research including dry and wet towing modes, which are widely used for various ships, offshore platforms, buoys, and artificial islands. Abokowitz [10] laid the foundation of a nonlinear mathematical model of ship towing by expanding the external force on the ship into the Taylor's series of each moving component, and accurately derived the precise mathematical model of each moving component. Charters et al. [11] introduced the concept of the towing course stability index by calculating the key towing force of stable towing and discussing the influence of towing cable length and towing speed. Krikelis and Kavouras [12] used the rudder controller proposed by Abkowitz [10] to analyze the stability and safety of a towing system under different sea conditions. Yan et al. $[13,14]$ conducted a model test on the same towing system, and established the governing equation of the motion of the towing system composed of "tugboat towing-cable-towed ship" in calm water and waves based on the hypothesis and semi-empirical formula. Bae [15] used the high-order boundary element method to numerically simulate the FPSO (floating production storage and offloading) under the interaction of nonlinear wave-flow, and calculated the diffraction and radiation wave in the time domain.

In order to ensure the structural safety of the ship-foundation system in the process of transportation, it is necessary to establish a one-step transportation structural health monitoring (SHM) system. In recent years, the SHM system has been widely studied and applied to ensure the availability, reliability, and profitability of a wind turbine structure. Rolfes et al. [16] equipped a wireless SHM system on a wind turbine to collect structural data for damage detection. Ciang et al. [17] summarized and compared various damage detection and evaluation methods applied to the wind turbine structure. Smarsly et al. [18] built a life management system including data acquisition, distributed software system, intelligent self-diagnosis system, model framework, and remote management system on a $500 \mathrm{~kW}$ wind turbine. Simultaneously, Hu $[19,20]$ studied the influence of the environment and operation on the dynamic characteristics of the structure based on the dynamic response signals of the $5 \mathrm{MW}$ wind turbine under normal operating conditions. Dong et al. [21] took the measured data of a 2.5 MW wind turbine to study the structural response rules of the turbines under different operating conditions, especially during extreme operating conditions.

The previous research studies have focused on the towing method of a traditional structure and the SHM system of offshore wind turbines in operation and extreme working conditions and lack analyses on the one-step overall transportation of CBF for offshore wind turbines. Therefore, we established the SHM system for the one-step overall transportation of CBF for offshore wind turbines based on the wind turbine transportation process at the Dafeng $300 \mathrm{MW}$ wind farm, China. Furthermore, the dynamic response of the CBF wind turbine was discussed to assess the CBF "foundation lift ship" transportation reliability by analyzing and discussing the prototype observation data. Based on the analysis of the prototype observation data, we propose a set of environment-vibration prediction systems for the one-step overall transportation of CBF by using the method of multiple linear regression. 


\section{One-Step Overall Transportation Technology}

\subsection{Project Conceptual Design}

According to the results of structural design and environmental characteristics, three towing methods were put forward in the preliminary analysis stage: single-foundation wet towing, boat-foundation dry towing, and "foundation lift ship" wet towing. The specific towing conceptual designs are shown in Figure 2.
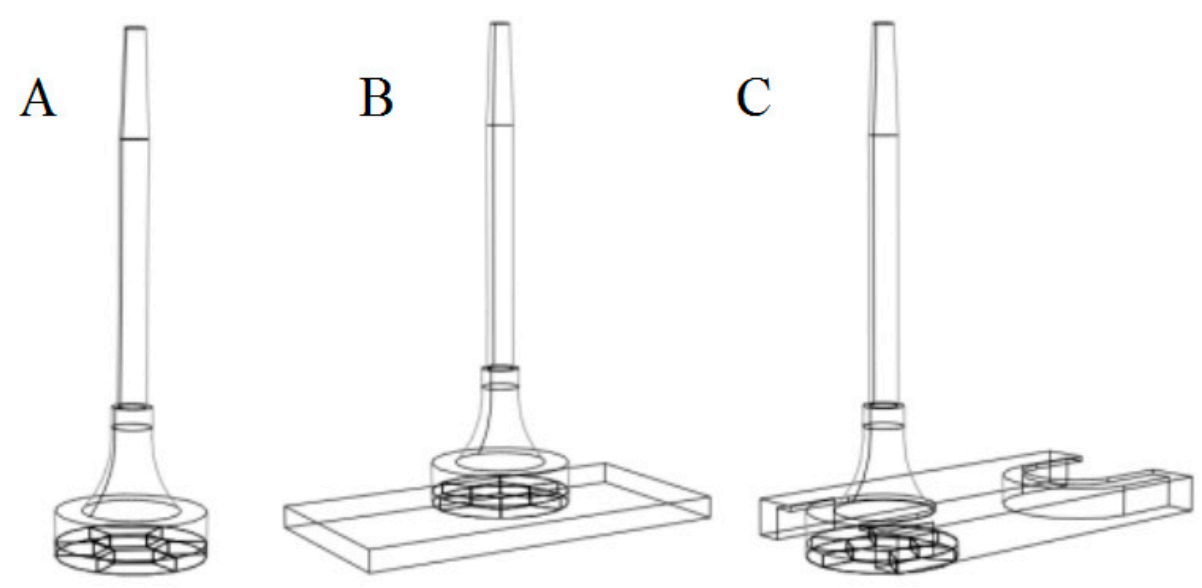

Figure 2. Conceptual design of the towing modes. (A) Single-foundation wet towing. (B) Boat-foundation dry towing. (C) "Foundation lift ship" wet towing.

In the analysis, the same feature sizes of $\mathrm{CBF}$, wind turbines, and dedicated ships were used in the three methods.

The initial stabilities of three different towing modes were calculated based on the traditional floating body theory, and the results are shown in Table 1 . When calculating the barycentric coordinates and buoyancy coordinates, the water surface is the coordinate zero.

Table 1. The initial stabilities of different conceptual designs.

\begin{tabular}{cccc}
\hline Item & A & B & C \\
\hline Weight $(\mathrm{t})$ & 3850 & 8280 & 8300 \\
Draught $(\mathrm{m})$ & 7.8 & 1.55 & 2 \\
Barycentric coordinates $(\mathrm{m})$ & 21.7 & 16.0 & 13.4 \\
Buoyancy coordinates $(\mathrm{m})$ & -2.4 & -0.775 & -1 \\
Initial stability height $(\mathrm{m})$ & -0.7 & 125.9 & 39.7 \\
\hline
\end{tabular}

Note: (A) Single-foundation wet towing conceptual design. (B) Boat-foundation dry towing conceptual design.

(C) "Foundation lift ship" wet towing conceptual design.

It can be seen from Table 1 that the center of gravity of the single-foundation wet towing mode was higher than the metacentric position, and the initial stability was negative, which makes the structure unable to be towed. Meanwhile, the boat-foundation dry towing mode and "foundation lift ship" wet towing mode both had preliminary feasibility, which makes the structure suitable to be towed.

ANSYS ${ }^{\circledR}$-AQWA (ANSYS18.2, ANSYS, Inc., Pittsburgh, PA, USA) was used to analyze the system motion of the boat-foundation dry towing mode and the "foundation lift ship" wet towing mode under the sea conditions: slight $(6 \mathrm{~m} / \mathrm{s}$ wind speed, $1 \mathrm{~m}$ wave height), rough $(10 \mathrm{~m} / \mathrm{s}$ wind speed, $2.5 \mathrm{~m}$ wave height), and high ( $20 \mathrm{~m} / \mathrm{s}$ wind speed, $4 \mathrm{~m}$ wave height), as shown in Table 2. 
Table 2. Maximum for each sea condition.

\begin{tabular}{ccccccc}
\hline \multirow{2}{*}{ Item } & \multicolumn{2}{c}{ Slight } & \multicolumn{2}{c}{ Rough } & \multicolumn{2}{c}{ High } \\
\cline { 2 - 7 } & B & C & B & C & B & C \\
\hline Pitch angle $\left(^{\circ}\right)$ & 0.67 & 0.79 & 1.69 & 5.65 & 2.70 & 16.73 \\
Heave (m) & 0.16 & 0.37 & 0.39 & 3.28 & 0.63 & 10.12 \\
Horizontal acceleration (g) & 0.011 & 0.020 & 0.029 & 0.102 & 0.049 & 0.273 \\
Vertical acceleration (g) & 0.011 & 0.013 & 0.029 & 0.040 & 0.045 & 0.083 \\
\hline
\end{tabular}

Note: (B) Boat-foundation dry towing. (C) "Foundation lift ship" wet towing.

It can be seen that under the same sea conditions, the boat-foundation dry towing mode was more stable. However, a large floating crane is required for auxiliary installation after dry towing transportation, which will increase the time and cost of installation at sea. Thus, the wet towing mode of the "foundation lift ship" is more profitable and was selected at the Dafeng offshore wind farms.

\subsection{Project Prototype}

The one-step overall transportation system at the Dafeng wind farm based on CBF was developed and elaborated as follows. The system included a 3.45 MW wind turbine and dedicated ship, as shown in Figure 3.

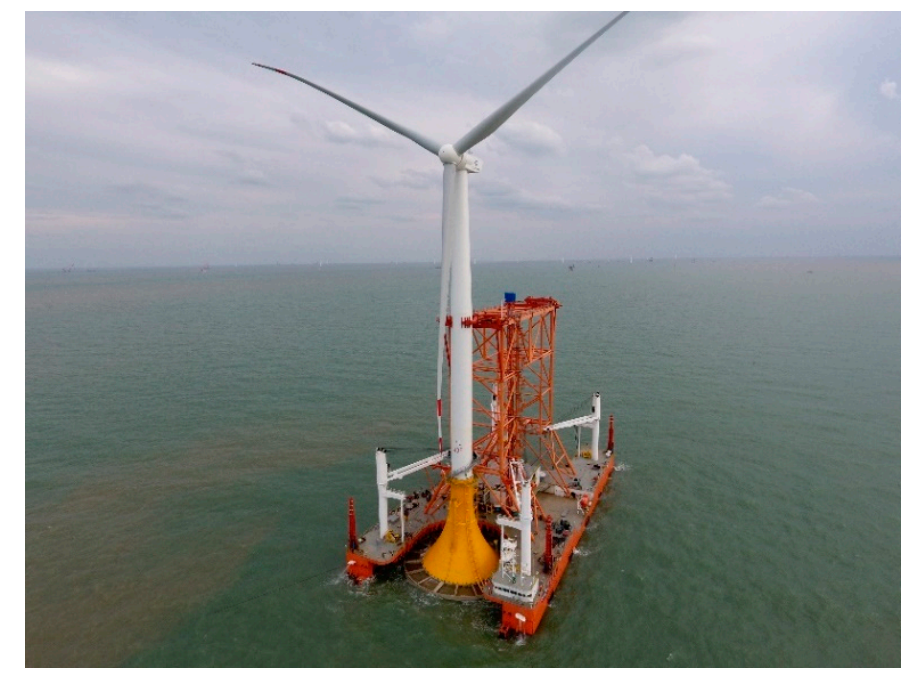

Figure 3. Photo of a prototype one-step transportation system for the CBF wind turbine.

The CBF has a diameter of $32 \mathrm{~m}$, height of $11 \mathrm{~m}$, and weight of $3150 \mathrm{t}$. The cabins, which are closely related to the motion stability and towing reliability of the $C B F$, include six side cabins of the same size and a regular hexagonal larger middle cabin (Figure 4). Unlike a traditional solid floating body, which is always regarded as a rigid foundation supported on water cushion, the CBF is equivalent to a flexible foundation supported by the coupling of a compressible air spring and water cushion. 


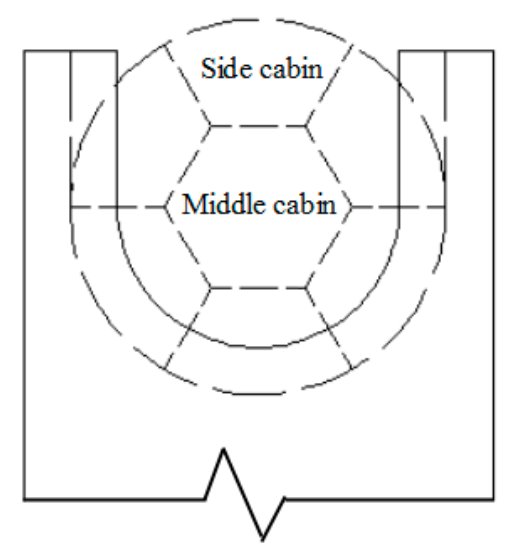

Figure 4. Diagram of the internal cabin of the CBF.

The rotor hub of a $3.45 \mathrm{MW}$ wind turbine is $92 \mathrm{~m}$ high above the flange face with the blade diameter of $140.36 \mathrm{~m}$ and a total weight of approximately $700 \mathrm{t}$. The wind turbine is connected to the $\mathrm{CBF}$ through the bottom flange ring. The blades are locked during the entire transportation and installation process.

The dedicated ship in the one-step overall transportation was $103.2 \mathrm{~m}$ long, $51.6 \mathrm{~m}$ wide, and $9 \mathrm{~m}$ deep, with a designed draft of $6 \mathrm{~m}$ (as shown in Figure 5). The CBF was closely fitted with the grid and sleeper in the front and back symmetrical openings of the dedicated ship through the extra buoyancy of the air in the cabin, which exceeded the gravity of the overall CBF and wind turbine. During the whole process of transportation, the CBF has at least a $500 \mathrm{t}$ upper lifting force on the ship to adjust the cabin pressure. In addition, three lifting points distributed at $120^{\circ}$ were set on the top cover of the $\mathrm{CBF}$, which were connected with the yawing righting winch on the ship. Meanwhile, each sling always maintains a lifting force of at least $10 \mathrm{t}$. At the lifting point at the connection between the CBF arc transition section and the transition top cover, five yawing preventing winches were connected with the dedicated ship. The $60 \mathrm{~m}$ high trusses were equipped with open and closed hoops that fit the tower. During the whole transportation process, the hoops fit the tower tightly.

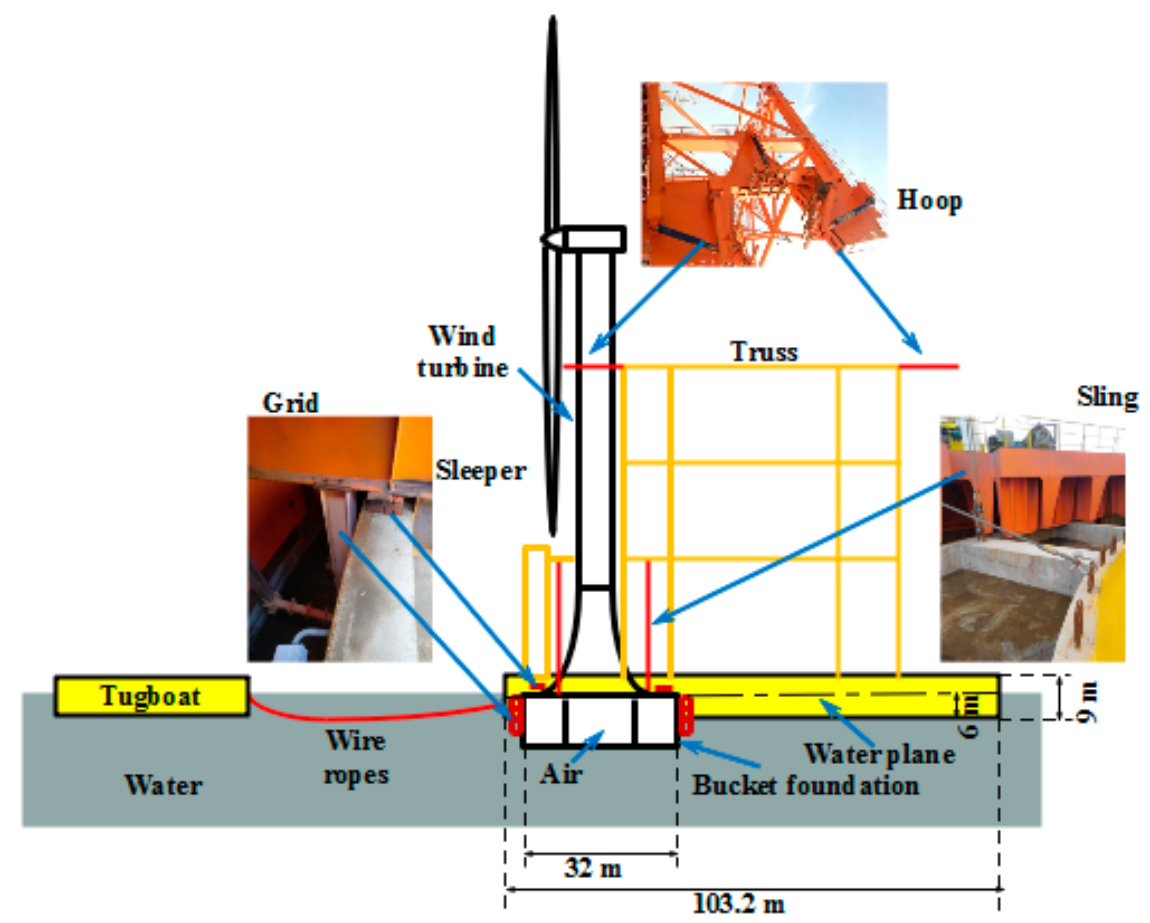

Figure 5. The one-step transportation system. 


\section{The Structural Health Monitoring System of Composite Bucket Foundation}

The CBF SHM system consists of three parts: the test system, acquisition system, and management system.

\subsection{Test System}

The test system was installed both inside the wind turbine and on the ship and included the wind turbine sensor system and the environmental sensor system. There are seven types of sensors inside the wind turbine: the accelerometer, displacement transducer, inclinometer, strain gauge, vibrating wire steel meter, vibrating wire concrete meter, and air pressure transmitter. The overall layout of sensors at each measuring point is shown in Figure 6. Environmental sensors including wind meters, wave height meters, and current meters were installed on the dedicated ship.

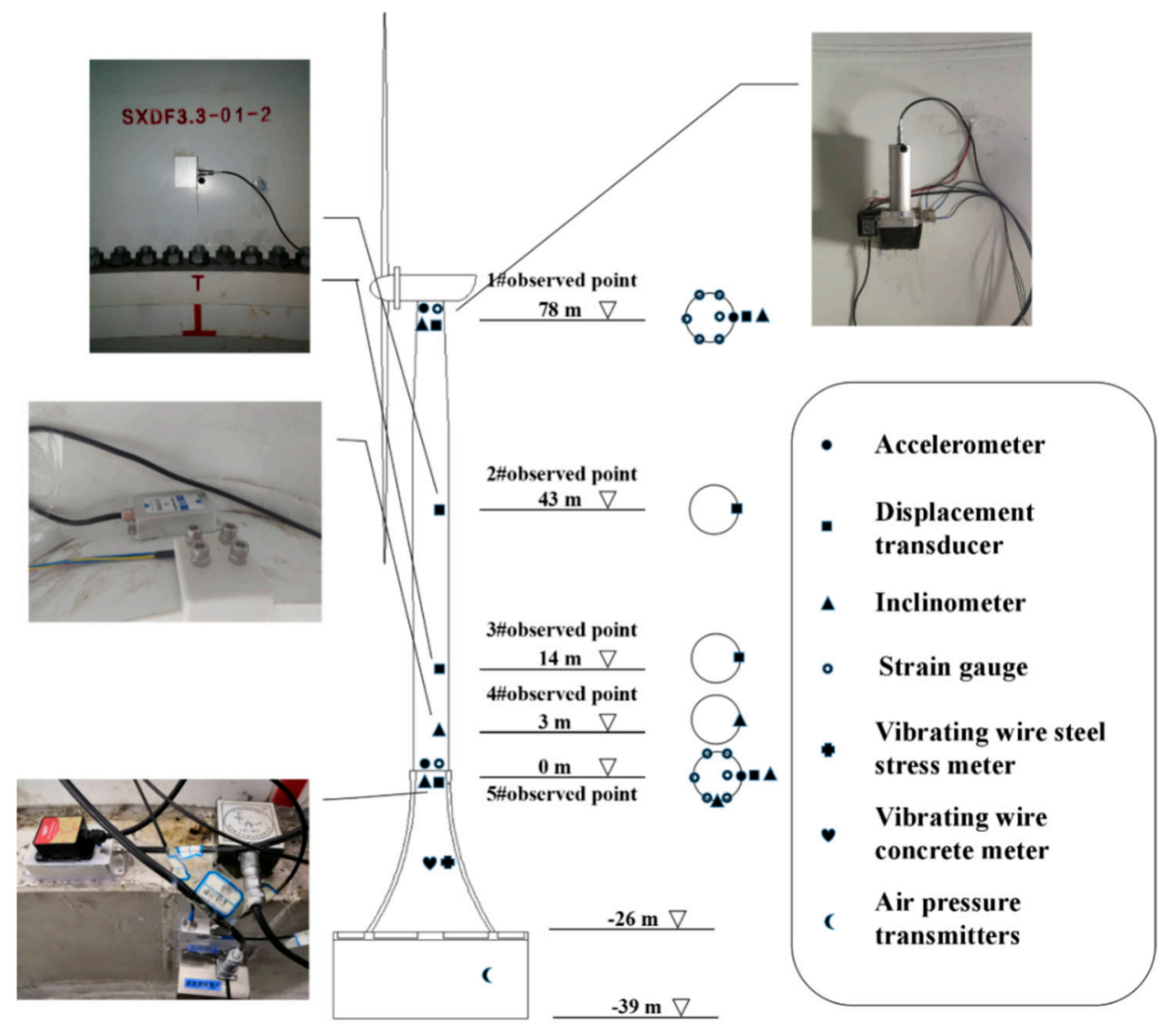

Figure 6. Layout of the test system.

\subsection{Acquisition System}

The acquisition system is divided into the internal wind turbine storage system and external wind turbine reading and control system. The monitoring data collected by the wind turbine test system are stored in the internal storage system and delivered to the PC terminal on the control platform of the dedicated ship in real time through an optical fiber.

The internal storage system, which is based on the JYL-8066 comprehensive data acquisition unit independently developed by Tianjin University (as shown in Figure 7), can compress and store original data collected for three years. The wind turbine external reading and control system mainly realizes three main functions: First, the real-time observation data signal presets the alarm value of each channel and sends a reminder when the real-time data of the channel exceeds the warning value; second, it can download and export data of any period of time to form data charts and graphs, therefore researchers can quickly conduct data processing and comparison; and third, the acquisition parameters 
and settings of the internal storage can be modified. In the transportation and installation process, the dynamic signal acquisition frequency is $200 \mathrm{~Hz}$ and the static signal acquisition frequency is $0.1 \mathrm{~Hz}$.

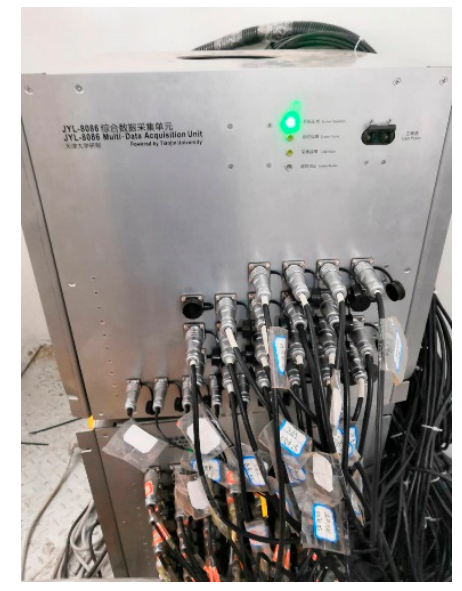

Figure 7. JYL-8066 integrated data acquisition unit.

\subsection{Management System}

The management system is divided into two parts: the ship management system and CBF management system. The behavior of the dedicated ship and CBF in the process of transportation and installation is managed and controlled by the real-time feedback of the acquisition system.

The ship management system mainly adjusts the ship's speed, heading, and draft during the voyage as well as the anchor positioning during the installation process.

The CBF management system includes the cabin pressure management system and the CBF limit system. The cabin pressure management can adjust cabin pressure in real-time, according to the data collected by sensors. The limit system of CBF includes the hoop between the first tower and the second tower, five yawing preventing winches, and three $100 \mathrm{t}$ yawing righting winches.

\section{Results and Discussion}

During the entire transportation process, several hypotheses were put forward in order to study the transportation stage.

Hypothesis 1. The system is assumed to go against the wave and flow during the transportation since it is the safest mode [22]. The speed and course are adjusted according to this assumption in the actual transportation process.

Hypothesis 2. The natural sea state is difficult to characterize due to its rapid change and irregular nature. Generally speaking, for practical offshore projects, sea conditions are considered as a stationary random process within a limited time period from $0.5 \mathrm{~h}$ to $10 \mathrm{~h}[23,24]$. The wind speed $U_{T, z}$ in the transportation process is determined as the average wind speed in $0.5 \mathrm{~h}$, which is measured $10 \mathrm{~m}$ above the upper deck. The current speed $U_{c}$ is taken as the average of the current speed in $0.5 \mathrm{~h}$. The wave height $H_{1 / 3}$ is the mean wave height of the highest third of the waves collected in $0.5 \mathrm{~h}$.

Due to the long duration and high frequency of data collection, there is a large amount of measured data during the whole process. Therefore, it is necessary to select typical working conditions and comparative working conditions to analyze the influences of three environmental factors in the transportation process. The threshold of the whole system is the nacelle acceleration $(0.25 \mathrm{~g}$ horizontal acceleration and $0.2 \mathrm{~g}$ vertical acceleration, which are provided by the wind turbine manufacturer), and the following analysis takes the nacelle acceleration as the main index. 


\subsection{Single Environment Variable Analysis}

\subsubsection{Current Speed}

Three working conditions, as shown in Table 3, were selected to analyze the influence of current speed on the acceleration at the nacelle.

Table 3. Current speed conditions.

\begin{tabular}{cccc}
\hline Working Condition & Wind Speed $(\mathbf{m} / \mathbf{s})$ & Wave Height $(\mathbf{m})$ & Current Speed $(\mathbf{m} / \mathbf{s})$ \\
\hline Condition 1 & 8.8 & 1.2 & 1.5 \\
Condition 2 & 8.1 & 1.1 & 1.0 \\
Condition 3 & 7.9 & 1.1 & 1.2 \\
\hline
\end{tabular}

The frequency domain signal was obtained by Fourier transform of the original time domain signals collected by the sensor. The time-frequency domain signals are listed in Figure 8 for the following data analysis. The time histories of $100 \mathrm{~s}$ depicted duration is the sampling from which we obtained the power spectra. The following conditions were analyzed in this way, which will not be described further.
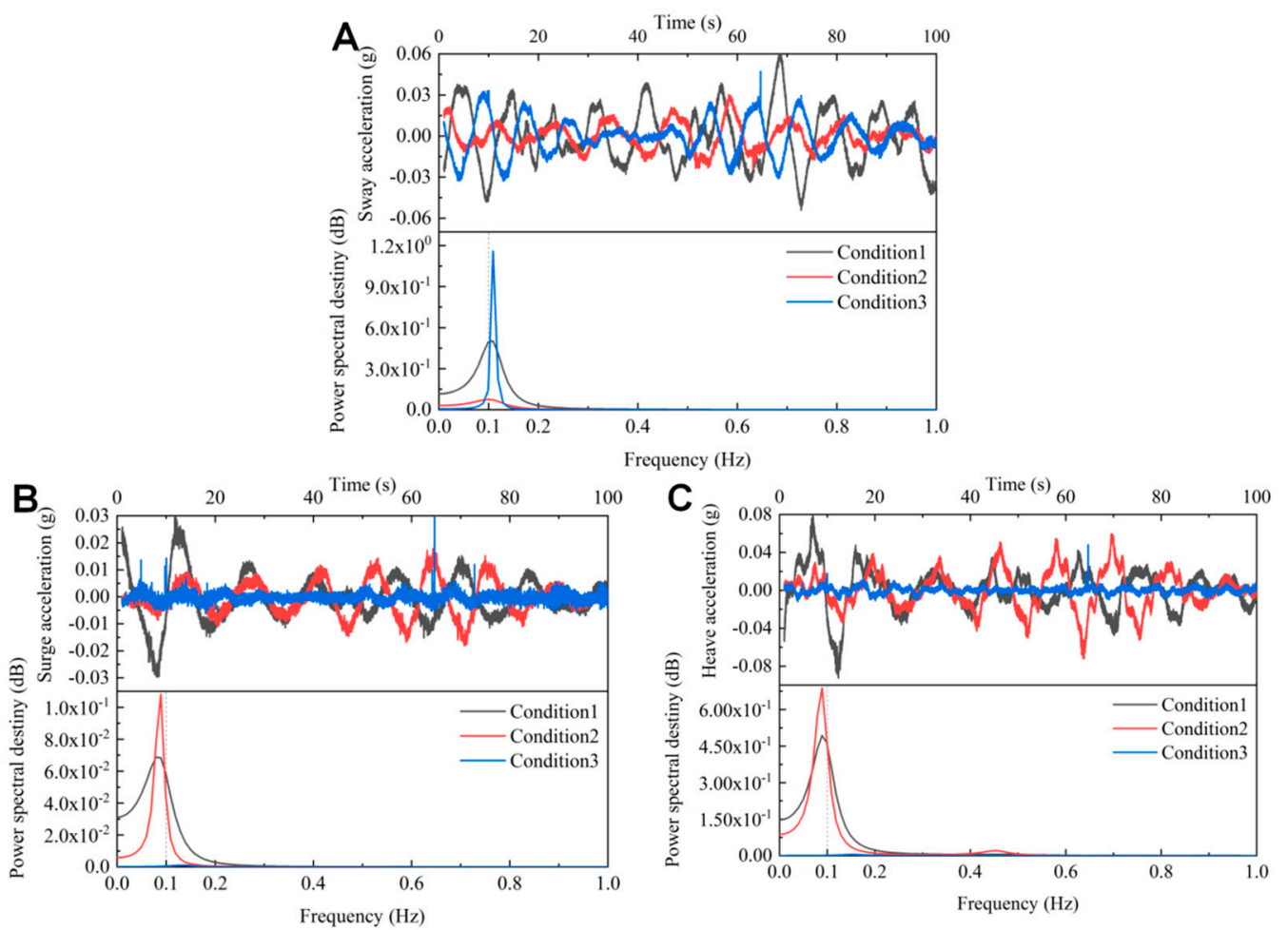

Figure 8. Nacelle acceleration and power spectral at different current speed. (A) Sway acceleration. (B) Surge acceleration. (C) Heave acceleration.

According to the time-frequency domain signal in Figure 8, the range of nacelle acceleration of the time-domain signal and the basic frequency of frequency-domain signal were extracted, and the data are listed in Table 4. 
Table 4. Range of nacelle acceleration and basic frequency at different current speed.

\begin{tabular}{cccc}
\hline Item & Condition 1 & Condition 2 & Condition 3 \\
\hline Range of sway acceleration $(\mathrm{g}) /$ Basic & {$[-0.054,0.0601]$} & {$[-0.0239,0.0303]$} & {$[-0.0328,0.0332]$} \\
frequency $(\mathrm{Hz})$ & 0.10891 & 0.09901 & 0.10891 \\
\hline Range of surge acceleration $(\mathrm{g}) /$ Basic & {$[-0.0296,0.0297]$} & {$[-0.0181,0.0178]$} & {$[-0.0062,0.0143]$} \\
frequency $(\mathrm{Hz})$ & 0.07921 & 0.08911 & 0.13861 \\
\hline Range of heave acceleration $(\mathrm{g}) /$ Basic & {$[-0.0925,0.079]$} & {$[-0.0719,0.0595]$} & {$[-0.0117,0.0178]$} \\
frequency $(\mathrm{Hz})$ & 0.08911 & 0.10891 & 0.15842 \\
\hline
\end{tabular}

According to Figure 8 and Table 4, the acceleration at the nacelle in all directions was less than the standard provided by the wind turbine manufacturer. The current speed affected the acceleration in all directions. With the increase in current speed, the maximum acceleration in all directions increased. The current speed had an obvious effect on the acceleration at the nacelle in the surge and heave direction, but not in the sway direction. The change in basic frequency was not obvious with the change of current speed, and it fell in the range of the natural wave frequency [25].

\subsubsection{Wind Speed}

Three working conditions, as shown in Table 5, were selected to analyze the influence of wind speed on the acceleration at the nacelle, and the results are shown in Figure 9 and Table 6.

Table 5. Wind speed conditions.

\begin{tabular}{cccc}
\hline Working Condition & Wind Speed $(\mathbf{m} / \mathbf{s})$ & Wave Height $(\mathbf{m})$ & Current Speed $(\mathbf{m} / \mathbf{s})$ \\
\hline Condition 4 & 12.3 & 1.3 & 0.9 \\
Condition 5 & 5.1 & 1.4 & 0.9 \\
Condition 6 & 7.7 & 1.4 & 1.0 \\
\hline
\end{tabular}
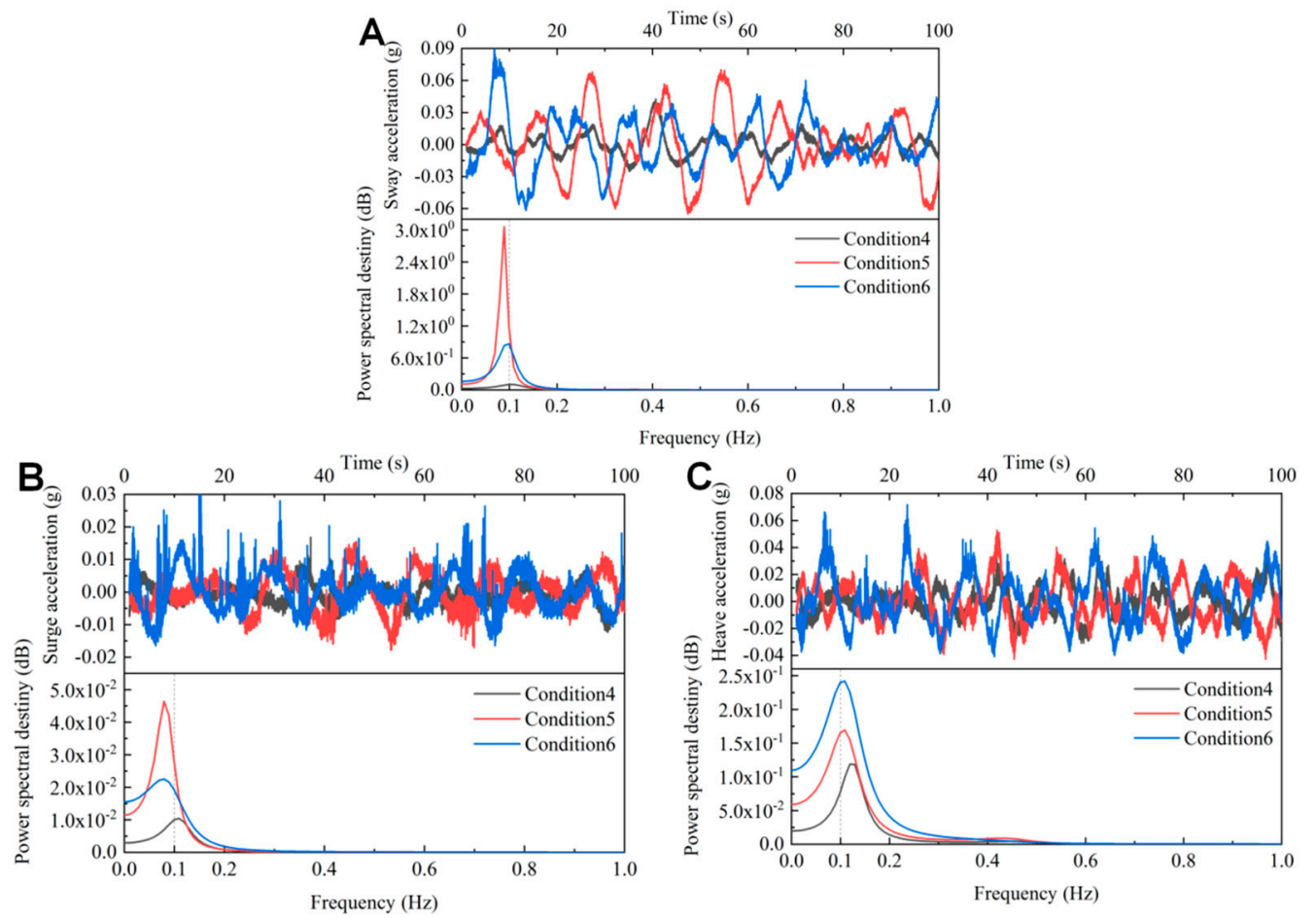

Figure 9. Nacelle acceleration and power spectral at different wind speed. (A) Sway acceleration. (B) Surge acceleration. (C) Heave acceleration. 
Table 6. Range of nacelle acceleration and basic frequency at different wind speed.

\begin{tabular}{cccc}
\hline Item & Condition 4 & Condition 5 & Condition 6 \\
\hline Range of sway acceleration $(\mathrm{g}) /$ Basic & {$[-0.0252,0.0425]$} & {$[-0.0649,0.07]$} & {$[-0.0617,0.0934]$} \\
frequency $(\mathrm{Hz})$ & 0.10891 & 0.08911 & 0.09901 \\
\hline Range of surge acceleration $(\mathrm{g}) /$ Basic & {$[-0.0123,0.0168]$} & {$[-0.0178,0.0155]$} & {$[-0.0165,0.0303]$} \\
frequency $(\mathrm{Hz})$ & 0.10891 & 0.07921 & 0.07921 \\
\hline Range of heave acceleration $(\mathrm{g}) /$ Basic & {$[-0.0421,0.0373]$} & {$[-0.0428,0.0527]$} & {$[-0.0409,0.0716]$} \\
frequency $(\mathrm{Hz})$ & 0.11881 & 0.10891 & 0.10891 \\
\hline
\end{tabular}

As can be seen from Figure 9 and Table 6, the acceleration at the nacelle in all directions was less than the standard provided by the wind turbine manufacturer. The wind speed had no obvious influence on the acceleration in all directions. The change of basic frequency was not apparent with the change of wind speed, and it fell in the range of natural wave frequency.

\subsubsection{Wave Height}

Three working conditions, as shown in Table 7, were selected to analyze the influence of wave height on the acceleration at the nacelle, and the results are shown in Figure 10 and Table 8.

Table 7. Wave height conditions.

\begin{tabular}{cccc}
\hline Working Condition & Wind Speed $(\mathrm{m} / \mathbf{s})$ & Wave Height $(\mathbf{m})$ & Current Speed $(\mathrm{m} / \mathbf{s})$ \\
\hline Condition 7 & 8.3 & 1.7 & 1.0 \\
Condition 8 & 8.2 & 1.5 & 0.9 \\
Condition 9 & 8.2 & 0.2 & 1.1 \\
\hline
\end{tabular}
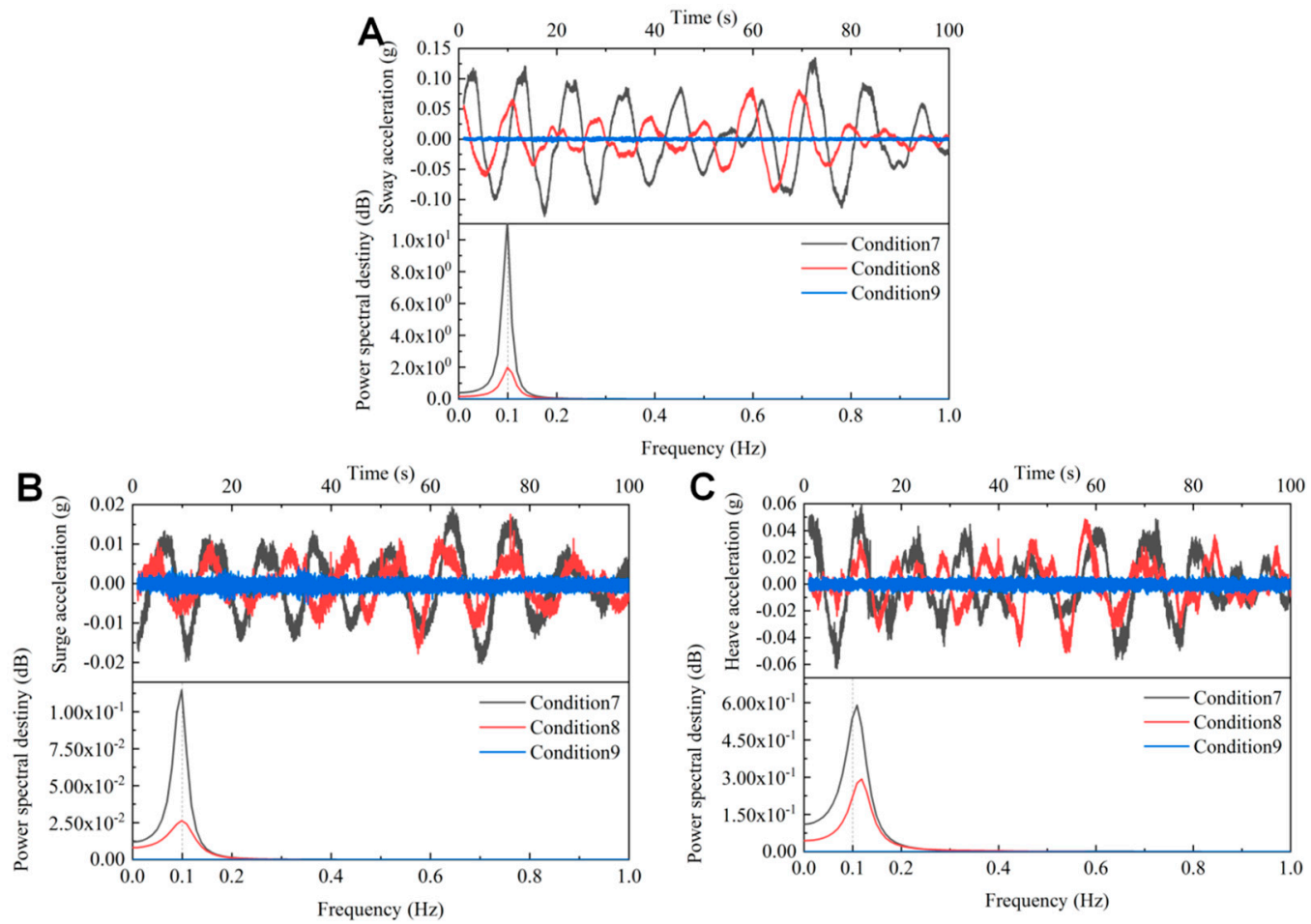

Figure 10. Nacelle acceleration and power spectral at different wave height. (A) Sway acceleration. (B) Surge acceleration. (C) Heave acceleration. 
Table 8. Range of nacelle acceleration and basic frequency at different wave height.

\begin{tabular}{cccc}
\hline Item & Condition 7 & Condition 8 & Condition 9 \\
\hline Range of sway acceleration $(\mathrm{g}) /$ Basic & {$[-0.1274,0.1344]$} & {$[-0.0883,0.0848]$} & {$[-0.0053,0.0053]$} \\
frequency $(\mathrm{Hz})$ & 0.09901 & 0.09901 & 0.45545 \\
\hline Range of surge acceleration $(\mathrm{g}) /$ Basic & {$[-0.0203,0.0194]$} & {$[-0.0178,0.0175]$} & {$[-0.0053,0.0043]$} \\
frequency $(\mathrm{Hz})$ & 0.09901 & 0.09901 & 0.06931 \\
\hline Range of heave acceleration $(\mathrm{g}) /$ Basic & {$[-0.063,0.0604]$} & {$[-0.0514,0.0486]$} & {$[-0.0088,0.0072]$} \\
frequency $(\mathrm{Hz})$ & 0.10891 & 0.11881 & 0.49505 \\
\hline
\end{tabular}

As can be seen from Figure 10 and Table 8, the acceleration at the nacelle in all directions was less than the standard provided by the wind turbine manufacturer. The wave height had a great influence on the acceleration in all directions. As the wave height increased, the acceleration in all directions obviously increased. The wave height had an obvious effect on the acceleration at the nacelle in all directions. The change of basic frequency was not apparent with the change in wave height at Conditions 7-8, and it fell in the range of natural wave frequency. For Condition 9, we believe that the signal energy was small and there may be other vibration sources.

\subsection{Limit Conditions Analysis}

\subsubsection{Nacelle Acceleration}

The maximum horizontal synthetic acceleration and vertical acceleration across the whole transportation process were selected for analysis, as shown in Figure 11 and Tables 9 and 10.
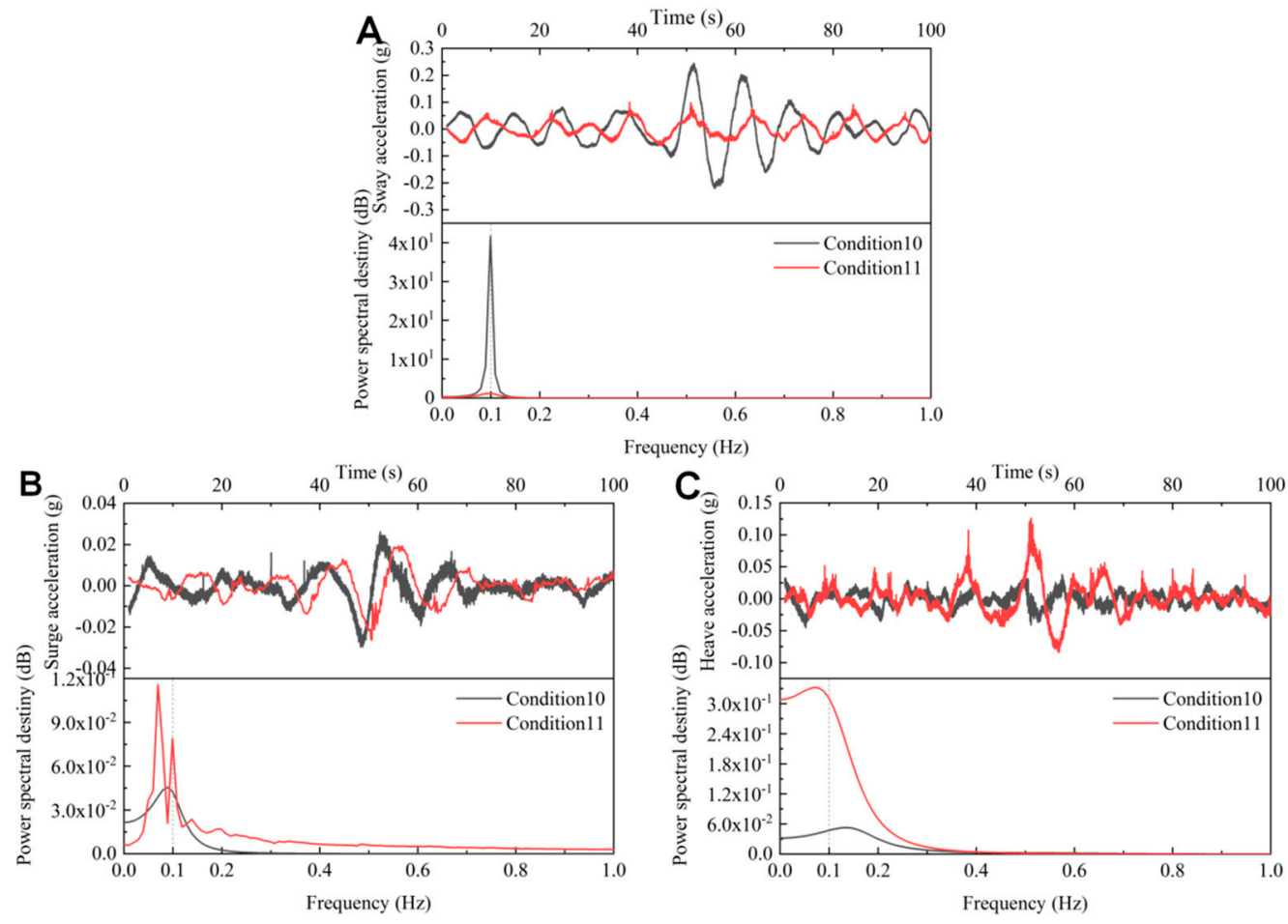

Figure 11. Nacelle acceleration and basic frequency at the limit conditions. (A) Sway acceleration. (B) Surge acceleration. (C) Heave acceleration. 
Table 9. Limit conditions.

\begin{tabular}{ccccc}
\hline $\begin{array}{c}\text { Working } \\
\text { Condition }\end{array}$ & $\begin{array}{c}\text { Wind Speed } \\
(\mathbf{m} / \mathbf{s})\end{array}$ & $\begin{array}{c}\text { Wave Height } \\
(\mathbf{m})\end{array}$ & $\begin{array}{c}\text { Current Speed } \\
(\mathbf{m} / \mathbf{s})\end{array}$ & Remark \\
\hline Condition 10 & 8.1 & 2.2 & 1.4 & $\begin{array}{c}\text { The maximums of horizontal } \\
\text { synthetic acceleration } \\
\text { The maximums of vertical } \\
\text { acceleration }\end{array}$ \\
\hline
\end{tabular}

Table 10. Range of nacelle acceleration and basic frequency at limit conditions.

\begin{tabular}{ccc}
\hline Item & Condition 10 & Condition 11 \\
\hline Range of sway acceleration $(\mathrm{g})$ & {$[-0.2197,0.244]$} & {$[-0.061,0.0995]$} \\
Basic frequency $(\mathrm{Hz})$ & 0.09901 & 0.09901 \\
Range of surge acceleration $(\mathrm{g})$ & {$[-0.0296,0.0261]$} & {$[-0.0312,0.047]$} \\
Basic frequency $(\mathrm{Hz})$ & 0.08911 & 0.06931 \\
Range of heave acceleration $(\mathrm{g})$ & {$[-0.0453,0.0377]$} & {$[-0.0841,0.1261]$} \\
Basic frequency $(\mathrm{Hz})$ & 0.13861 & 0.06931 \\
\hline
\end{tabular}

The acceleration at the nacelle in all directions (Table 10) was less than the standard provided by the wind turbine manufacturer. The maximum horizontal acceleration encountered in this transportation, which occurs in operating condition 10 , was about $0.246 \mathrm{~g}$ and slightly less than the standard $0.25 \mathrm{~g}$ set by the wind turbine manufacturer. The maximum vertical acceleration encountered in this transportation, which occurs in working condition 11 , was about $0.126 \mathrm{~g}$ and less than the $0.2 \mathrm{~g}$ standard set by the wind turbine manufacturer. The basic frequency fell in the range of natural wave frequency.

\subsubsection{Entirety Acceleration and Displacement}

The changes of acceleration and displacement of each observed point shown in Figure 6 under the limit condition were compared, as shown in Figures 12 and 13.
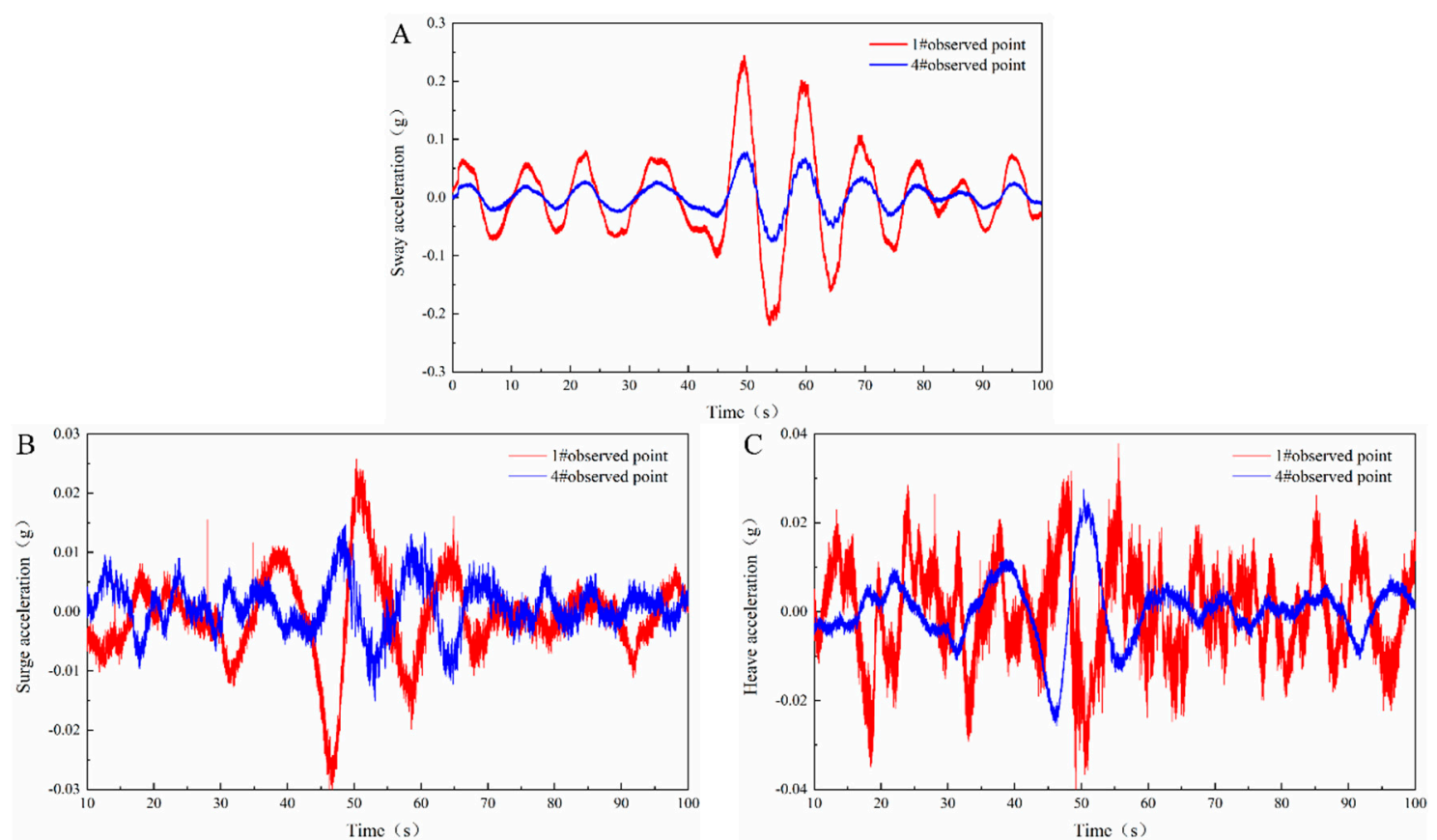

Figure 12. Acceleration of each observed point at limit conditions. (A) Sway acceleration. (B) Surge acceleration. (C) Heave acceleration. 

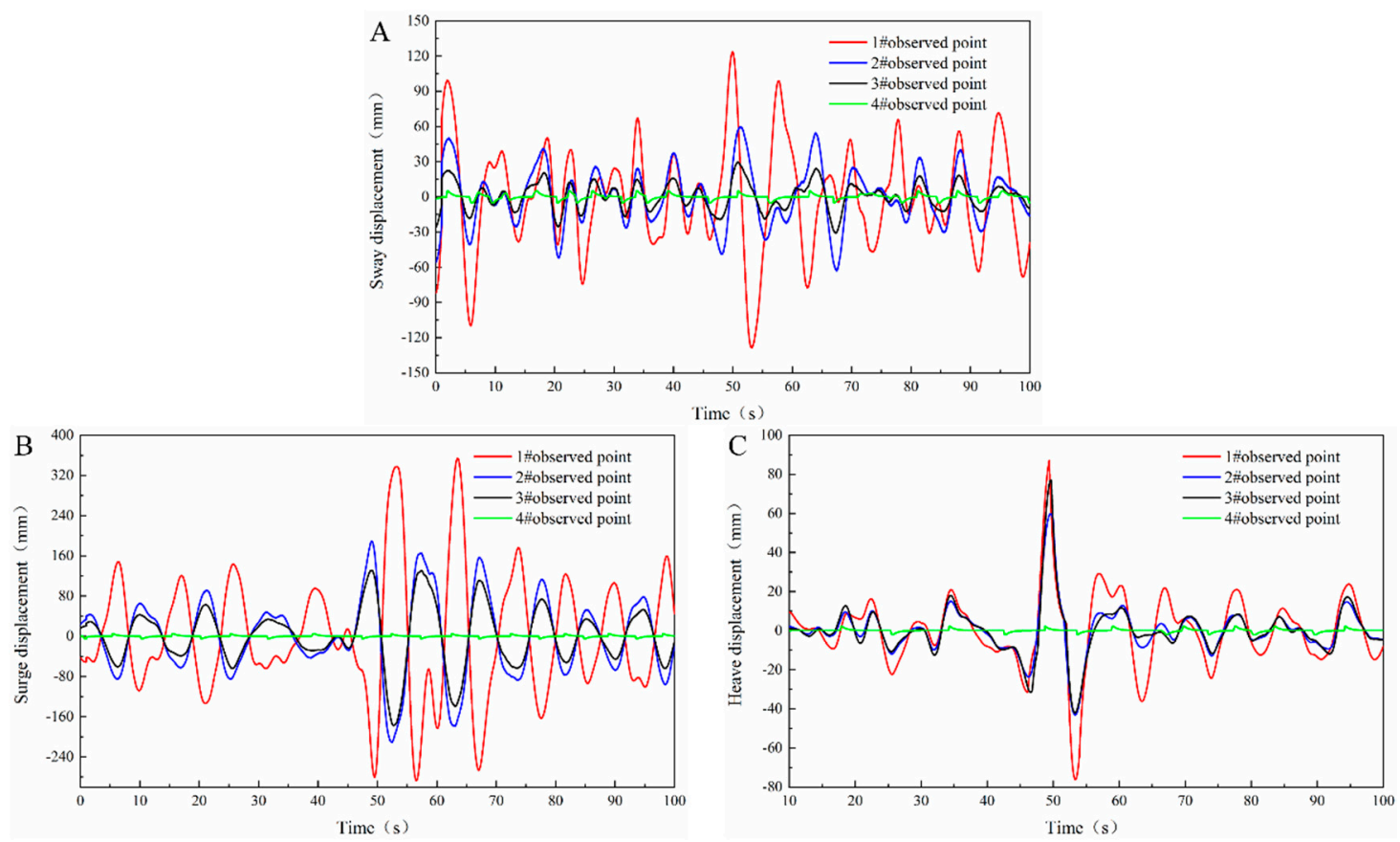

Figure 13. Displacement of each observed point in limit conditions. (A) Sway displacement. (B) Surge displacement. (C) Heave displacement.

It can be seen from the figure that the acceleration and vibration displacement at the nacelle in all directions were larger than those at the top of the foundation. In the sway direction, the acceleration and vibration displacement time history of each observed point were basically in the same phase. The limit system such as hoop and gird plays a great role. In the surge direction, phase differences occur between the acceleration time history and displacement time history at each observed point. Uncoordinated motions appear, but the motion amplitude is within the safe range. In the heave direction, phase differences occur between the acceleration time histories of each observed point, while the displacement time histories are basically in the same phase. The limit system is beneficial in ensuring the consistency of ship-foundation displacement in the direction of heave, and indirectly ensuring the stability of cabin pressure.

\subsection{Wind-Wave-Current Coupling Analysis}

According to the working conditions and results listed above, shown in Tables 3-10, the absolute maximum acceleration in each working condition was taken to analyze the relationship between the acceleration and three kinds of environmental factors.

The multiple linear regression method is used to study the relationship between wind speed, wave height, current speed, and acceleration at the nacelle. According to Equations (1) and (2) of the wind and current loads in the DNVGL-RP-C205 [26] specification, and Equation (3) of horizontal wave loads of the cylinder considering radiation force and diffraction force from Finnegan et al. [27], the wind speed term $X_{\text {wind }}\left(U_{T, z}^{2}\right)$, wave height term $X_{\text {wave }}\left(H_{1 / 3}\right)$, and current speed term $X_{\text {current }}\left(U_{C}^{2}\right)$ are determined as follows:

$$
\begin{gathered}
F_{\text {CURRENT }}=C U_{c}^{2} \\
\left\{\begin{array}{l}
q=\frac{1}{2} \rho U_{T, z}^{2} \\
F_{\text {WIND }}=C q S \sin \alpha
\end{array}\right\} \\
\left\{\begin{array}{l}
F_{W A V E}=|F| \cos (\omega t+\beta) \\
F=-\frac{2 \pi \rho g A a}{k_{0}}\left\{\mathrm{~J}_{1}\left(k_{0} a\right)-\mathrm{J}^{\prime}{ }_{1}\left(k_{0} a\right) \frac{\mathrm{H}_{1 / 3}^{(1)}\left(k_{0} a\right)}{\mathrm{H}_{1 / 3}^{(1)}\left(k_{0} a\right)}\right\}\left(1-e^{-k_{0} b}\right)
\end{array}\right\}
\end{gathered}
$$


In Equation (2), $C$ refers to the shape coefficient; $q$ is the basic wind pressure or suction; $S$ is the projected area of the member normal to the direction of the force; $\alpha$ is the angle between the direction of the wind and the axis of the exposed member or surface. In Equation (3), $k_{0}$ is the wave number; $A$ is the amplitude of incident wave; $b$ is the draft of cylinder; $\alpha$ is the draft of cylinder; $J(x)$ is the Bessel formula of the first kind; and $H(x)$ is the Bessel formula of the third kind.

By using the multiple linear regression method, we can obtain the regression parameters, shown in Table 11. The independent variables refer to the wind speed, wave height, and current speed. The variables refer to the acceleration of three directions. Multiple $\mathrm{R}$ is the correlation coefficient, which refers to the degree of correlation between the independent variable and dependent variable. The closer the parameter is to 1.0 , the higher the correlation is between the independent variable and dependent variable. Significance F is the statistical significance. It is generally believed that if Significance $\mathrm{F}$ is less than 0.05 , the regression characteristic is significant. The $P$-value is the regression coefficients. $P$-value $<0.05$ indicates that the independent variable has significant influence on the dependent variable. The smaller the $p$-value, the more significant the independent variable affects the dependent variable.

Table 11. Regression parameters.

\begin{tabular}{|c|c|c|c|c|}
\hline \multicolumn{2}{|c|}{ Item } & Sway & Surge & Heave \\
\hline \multicolumn{2}{|c|}{ Multiple R } & 0.9032 & 0.6638 & 0.4452 \\
\hline \multicolumn{2}{|c|}{ Significance F } & 0.005774 & 0.2281 & 0.6483 \\
\hline \multirow{3}{*}{$p$-value } & Variable $_{\text {wind }}$ & 0.5901 & 0.6370 & 0.6708 \\
\hline & Variable $_{\text {wave }}$ & 0.001392 & 0.08952 & 0.2922 \\
\hline & Variable $_{\text {current }}$ & 0.2519 & 0.2519 & 0.8393 \\
\hline
\end{tabular}

From the above analysis, it can be seen that the regression coefficient of wave height was far smaller than other coefficients in the acceleration analysis of three directions, indicating that in the transportation process, wave height has the largest impact on the acceleration at the nacelle, followed by the current speed, and wind speed has the smallest impact on the acceleration, which is mutually consistent with the analysis of the frequency domain results.

The sway acceleration shows significant regression characteristics, while the surge and heave acceleration were not significant, which may be affected by the dedicated ship and gas spring. The above regression parameters can be used to estimate the acceleration at the nacelle under the wind-wave-current coupling.

The relationship between acceleration A at three directions and the wind speed term $X_{\text {wind }}\left(U_{T, z}^{2}\right)$, wave height term $X_{\text {wave }}\left(H_{1 / 3}\right)$, and current speed term $X_{\text {current }}\left(U_{C}^{2}\right)$ can be given by the following regression in Equations (4)-(6):

$$
\begin{aligned}
A_{\text {sway }} & =-0.08764-0.0001976 X_{\text {WIND }} \\
& +0.1115 X_{\text {WAVE }}+0.02783 X_{\text {CURRENT }} \\
A_{\text {surge }} & =0.002547-5.109 \mathrm{E}-05 X_{\text {WIND }} \\
& +0.01273 X_{\text {WAVE }}+0.005233 X_{\text {CURRENT }} \\
A_{\text {heave }} & =0.02883-0.0001627 X_{\text {WIND }} \\
& +0.02609 X_{\text {WAVE }}+0.004917 X_{\text {CURRENT }}
\end{aligned}
$$

According to the working Equations (4)-(6) for the working conditions 1-11, the acceleration in all directions were computed. Figure 14 shows the comparison between the computed and observed accelerations. According to Figure 14, it can be seen that in the case of a large wind-wave-current difference in various working conditions, the calculated value still showed little difference with the 
measured value. Therefore, we can estimate the acceleration at the nacelle in each direction during transportation according to Equations (4)-(6).

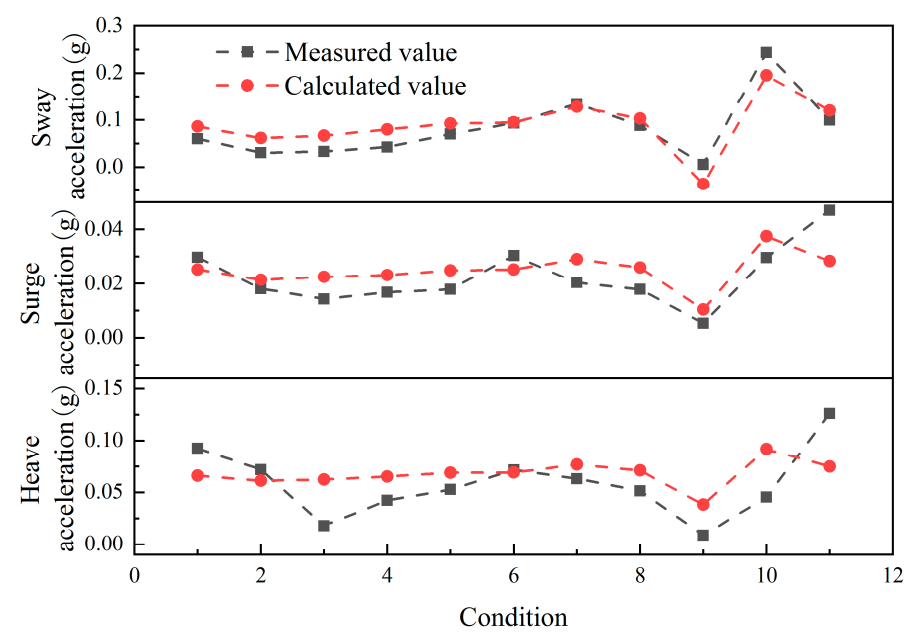

Figure 14. Calculated and measured values of acceleration in all directions.

According to Figure 14, it can be seen that in the case of large wind-wave-current difference in various working conditions, the calculated value still had little difference with the measured value. Therefore, we can estimate the acceleration at the nacelle in each direction during transportation according to Equations (4)-(6). In practical engineering, the formula can be used to combine the threshold of nacelle acceleration provided by different wind turbine manufacturers and the meteorological conditions provided by different wind farms to form an envelope surface of the nacelle acceleration between the wind-wave-flow combination. According to this envelope surface, we can make a transportation strategy under the premise of reserving the safety margin. The successful transportation of the Xiangshui and Dafeng wind farms also prove this point.

\section{Conclusions}

(1) Through the combined action of cabin pressure, auxiliary sling, bottom limit, and grid, the overall stability of the CBF and the ship in the whole transport process of "foundation lift ship" can be well guaranteed.

(2) The presence of a tower hoop is helpful in reducing the motion response at the nacelle. The maximum acceleration in three directions during the whole transport process can meet the requirements of the wind turbine manufacturer (horizontal acceleration $\leq 0.25 \mathrm{~g}$, vertical acceleration $\leq 0.2 \mathrm{~g}$ ).

(3) During transportation, the basic frequency of the acceleration of the nacelle is within the range of natural waves, and through numerical analysis and prototype monitoring, it was found that the motion response of the head is the most sensitive to wave height, followed by the current speed. As the wind turbine blade is in a state of braking during the transportation, the wind speed has little influence on it.

(4) The most severe sea state encountered in the Dafeng CBF transportation was a $12.3 \mathrm{~m} / \mathrm{s}$ wind speed and $2.2 \mathrm{~m}$ wave height. In the sway direction, the time histories of acceleration and vibration displacement at each of the observed points were basically in the same phase. In the surge direction, phase differences occurred between the time histories of acceleration and displacement at each observed point. Uncoordinated motions appeared, but the motion amplitude was within the safe range. In the heave direction, the acceleration time history of each observed point had a phase difference, and the displacement time histories were basically in the same phase.

(5) The sway acceleration showed significant regression characteristics, while the surge and heave acceleration were not significant, which may be affected by the dedicated ship and gas spring. 
The regression formula proposed can be used to estimate the nacelle acceleration under the wind-wave-current coupling state.

Through the monitoring of this transportation, we have enhanced our confidence in the one-step transportation of $\mathrm{CBF}$, and verified the results of our previous theoretical calculation and numerical simulation. We will also adjust the transportation strategy and carry out continuous verification according to the observation results.

Author Contributions: Conceptualization, J.L.; methodology, C.L., P.W. and Q.J.; formal analysis, C.L., P.W. and Q.J.; software, P.W.; resources, P.W. and X.D.; data curation, P.W. and X.D.; writing—original draft preparation, P.W.; writing-review and editing, P.W., C.L., Y.Y. and J.J.; supervision, J.L.; validation, C.L. and X.Y.; funding acquisition, J.L. and C.L. All authors have read and agreed to the published version of the manuscript.

Funding: This research was supported by the Fund for Innovation Method Fund of China (Grant No. 2016IM030100) and Tianjin Municipal Natural Science Foundation (Grant No. 18JCYBJC22800).

Acknowledgments: All workers from the State Key Laboratory of Hydraulic Engineering Simulation and Safety of Tianjin University are acknowledged. The writers acknowledge the assistance of anonymous reviewers as well.

Conflicts of Interest: The authors declare no conflicts of interest.

\section{References}

1. China National Energy Administration. Wind Power Development "13th Five-Year" Plan; China National Energy Administration: Beijing, China, 2016.

2. Lian, J.J.; Chen, F.; Wang, H.J. Laboratory tests on soil-skirt interaction and penetration resistance of suction caissons during installation in sand. Ocean Eng. 2014, 84, 1-13. [CrossRef]

3. Lian, J.J.; Ding, H.Y.; Zhang, P.Y.; Yu, R. Design of large-scale prestressing bucket foundation for offshore wind turbines. Trans. Tianjin Univ. 2012, 18, 79-184. [CrossRef]

4. Liu, R.; Chen, G.S.; Lian, J.J.; Ding, H.Y. Vertical bearing behaviour of the composite bucket shallow foundation of offshore wind turbines. J. Renew. Sustain. Energy 2015, 7, 013123. [CrossRef]

5. Ding, H.Y.; Liu, Y.G.; Zhang, P.Y.; Le, C.H. Model tests on the bearing capacity of wide-shallow composite bucket foundations for offshore wind turbines in clay. Ocean Eng. 2015, 103, 114-122. [CrossRef]

6. Ding, H.Y.; Li, Z.Z.; Lian, J.J.; Zhang, P.Y.; Huang, X. Soil reinforcement experiment inside large-scale bucket foundation in muddy soil. Trans. Tianjin Univ. 2012, 18, 168-172. [CrossRef]

7. Ding, H.Y.; Lian, J.J.; Li, A.D.; Zhang, P.Y. One-step-installation of offshore wind turbine on large-scale bucket-top-bearing bucket foundation. Trans. Tianjin Univ. 2013, 19, 188-194. [CrossRef]

8. Le, C.H.; Ding, H.Y.; Zhang, P.Y. Air-floating towing behaviors of multi-bucket foundation platform. China Ocean Eng. 2013, 27, 645-658. [CrossRef]

9. Lacal-Arántegui, R.; Yusta, J.M.; Domínguez-Navarro, J.A. Offshore wind installation: Analysing the evidence behind improvements in installation time. Renew. Sustain. Energy Rev. 2018, 92, 133-145. [CrossRef]

10. Abkowitz, M.A. Lectures on Ship Hydrodynamics-Steering and Maneuverability; Report Hy-5, Hydro- and Aerodynamic Laboratory: Lyngby, Denmark, 1964; p. 5. Available online: https://trid.trb.org/view/159100 (accessed on 16 July 2018).

11. Charters, S.; Thomas, G.; Latorre, R. Analysis of Towed Vessel Course Stability in Shallow Water; Royal Institution of Naval Architects Transactions: London, UK, 1986; p. 128. Available online: https://trid.trb.org/view/397972 (accessed on 16 July 2018).

12. Krikelis, N.J.; Kavouras, D. Dynamic performance of towed vessels employing nonlinear rudder control under adverse weather conditions. Int. Shipbuild. Prog. 1986, 33, 114-126. [CrossRef]

13. Yan, S.S.; Huang, G.Y. Numerical simulation of towering system's maneuvering motion in calm sea. Ship Build. China 1997, 4, 12-19.

14. Yan, S.S.; Huang, G.Y. Numerical simulation of towering system's maneuvering motion in wind sea. J. Ship Mech. 2001, 5, 13-24.

15. Bae, S.-Y. Numerical Simulation of Inviscid Wave-Current Interaction with an FPSO; Texas A\&M University: College Station, TX, USA, 2008. 
16. Rolfes, R.; Gerasch, G.; Haake, G.; Reetz, J.; Zerbst, S. Early damage detection system for tower and rotor blades of offshore wind turbines. In Proceedings of the 3rd European Workshop-Structural Health Monitoring 2006, Granada, Spain, 5-7 July 2006.

17. Ciang, C.C.; Lee, J.R.; Bang, H.J. Structural health monitoring for a wind turbine system: A review of damage detection methods. Meas. Sci. Technol. 2008, 19, 122001. [CrossRef]

18. Kay, S.; Dietrich, H.; Kincho, H.L. An Integrated Monitoring System for Life-Cycle Management of Wind Turbines. Int. J. Smart Struct. Syst. 2013, 12, 209-233.

19. Hu, W.H.; Thons, S.; Rohrmann, R.G.; Said, S.; Rücker, W. Vibration-based structural health monitoring of a wind turbine system. Part I: Resonance phenomenon. Eng. Struct. 2015, 89, 260-272. [CrossRef]

20. Hu, W.H.; Thons, S.; Rohrmann, R.G.; Said, S.; Rücker, W. Vibration-based structural health monitoring of a wind turbine system Part II: Environmental/operational effects on dynamic properties. Eng. Struct. 2015, 89, 273-290. [CrossRef]

21. Dong, X.F.; Lian, J.J.; Wang, H.J. Structural vibration monitoring and operational modal analysis of offshore wind turbine structure. Ocean Eng. 2018, 150, 280-297. [CrossRef]

22. Ding, H.Y.; Han, Y.Q.; Zhang, P.Y.; Huo, S.X. Effects of air pressure on stability of integrated transportation and installation vessel for offshore wind turbine. J. Tianjin Univ. Sci. Technol. 2017, 50, 915-920. [CrossRef]

23. Faltinsen, O. Sea Loads on Ships and Offshore Structures; Cambridge University Press: Cambridge, UK, 1993.

24. Molin, B. Hydrodynamique des Structures Offshore; Editions Technip: Paris, France, 2002.

25. Lombardi, D.; Bhattacharya, S.; Muir Wood, D.M. Dynamic soil structure interaction of monopile supported wind turbines in cohesive soil. Soil Dyn. Earthq. Eng. 2013. [CrossRef]

26. Veritas, D.N. DNV-RP-C205 Environmental Conditions and Environmental Loads; Det Norske Veritas: Oslo, Norway, 2017.

27. William, F.; Meere, M.; Goggins, J. The wave excitation forces on a truncated vertical cylinder in water of infinite depth. J. Fluids Struct. 2013, 40, 201-213. [CrossRef]

(C) 2019 by the authors. Licensee MDPI, Basel, Switzerland. This article is an open access article distributed under the terms and conditions of the Creative Commons Attribution (CC BY) license (http://creativecommons.org/licenses/by/4.0/). 